Check for updates

Cite this: RSC Adv., 2017, 7, 34901

Received 11th May 2017

Accepted 26th June 2017

DOI: 10.1039/c7ra05352e

rsc.li/rsc-advances

\section{Two new photochromic coordination compounds with nonphotochromic ligands and different metal centers $\uparrow$}

\begin{abstract}
Jie Liu, ${ }^{\text {ab }}$ Pei-Xin Li, ${ }^{* b}$ Hui-Yi Zeng ${ }^{b}$ and Guo-Cong Guo (iD *b
Recent research has demonstrated the effective synthesis of photochromic coordination compounds via the assembly of nonphotochromic ligands (electronic donors and acceptors) and a metal center (joint points). To enrich this system, the metal center could be expanded to binuclear or multinuclear, but related studies are rare. Two new photochromic coordination compounds with different metal joint dots were obtained using expanded metal centers. In this work, $\left[\mathrm{Zn}_{2}(\mathrm{Bpy})_{1.5}(\mathrm{CTA})_{4} \cdot 2 \mathrm{H}_{2} \mathrm{O}\right](1, \mathrm{CTA}=$ crotonic acid, Bpy $=4,4^{\prime}$-bipyridine) and $\left[\mathrm{Zn}_{2}(\mathrm{Bpy})(\mathrm{CTA})_{4}\right]$ (2) were synthesized under different $\mathrm{pH}$ conditions. Compound 1 features a 1-D chain structure with 4,4'-bipyridine coordinating to mono zinc ions and binuclear Zn units simultaneously. Compound 2 also features a 1-D chain structure, where only the binuclear $\mathrm{Zn}$ is bridged by the 4,4'-bipyridine. This work will help to obtain new and promising photochromic compounds with different multinuclear metal centers and high performance.
\end{abstract}

\section{Introduction}

Electron transfer (ET) photochromic materials have attracted great attention due to their increasing applications, such as catalysis and optic, electric, and magnetic switches. ${ }^{\mathbf{1 , 2}}$ In past decades, much effort has been concentrated on the traditional families of ET photochromic compounds, such as viologens and polyoxometalates of group VIB metals, due to their merits. ${ }^{3,4}$ In recent years, a new class of ET photochromic compounds has been composed of non-photochromic ligands and metal ions through coordination. ${ }^{5,6}$ These include metal-organic compounds (MOCs), with various functional materials based on MOCs having been produced with electronic, ${ }^{7}$ magnetic, ${ }^{8}$ and nonlinear optical ${ }^{9}$ characters. Therefore, exploring this type of photochromic species based on MOCs is valuable, and may offer new opportunities to enrich the system and obtain promising photochromic materials.

Few examples of photochromic compounds with nonphotochromic ligands have been reported. Their structures usually comprise metal ions and carboxylate groups connected by a coordinated conjugated ligand. Studies have reported the use of conjugated ligands, such as 4,4'-bipy, trigonal 3-connector 2,4,6tris(4-pyridyl)-1,3,5-triazine, 4,4'-bis(1-imidazolyl)-biphen, 1,3-

${ }^{a}$ Fuzhou University, Fuzhou, Fujian 350108, PR China

${ }^{b}$ State Key Laboratory of Structural Chemistry, Fujian Institute of Research on the Structure of Matter, Chinese Academy of Sciences, Fujian, Fuzhou, 350002, PR China.E-mail:gcguo@fjirsm.ac.cn; lipeixin@fjirsm.ac.cn

$\dagger$ Electronic supplementary information (ESI) available: Additional structural tables, PXRD patterns, TGA and luminescent decay curves, UV-Vis absorption spectra and excitation spectra. CCDC 1542261 and 1542260. For ESI and crystallographic data in CIF or other electronic format. See DOI: 10.1039/c7ra05352e di(4-pyridyl)propane, as electron acceptors, carboxylate as the electron donor, ${ }^{\mathbf{1 0 - 1 2}}$ and electron transfer from the carboxylate to the conjugated ligand via through-bond and through-space paths. ${ }^{13}$ The corresponding radicals could be trapped at room temperature in a photochromic (conjugated ligand-metalcarboxylate) system by photoexcitation. ${ }^{\mathbf{1 4}}$ Therefore, these compounds can be synthesized largely via ligand design for photochromic studies and applications. Furthermore, the influence of different metal ions on photosensitivity has been discovered by the Zhang group, ${ }^{15}$ whereas photosensitivity is seldom tuned through designing the metal centers in a dinuclear or trinuclear form. Works related to this have so far not been published.

As part of our research into the construction of solid photochromic materials via non-photochromic ligand design, ${ }^{\mathbf{1 6}}$ we investigated this type of photochromic compounds using multi-metal joint points. We obtained two new $\mathrm{Zn}$ (II) coordination compounds, $\left[\mathrm{Zn}_{2}(\mathrm{Bpy})_{1.5}(\mathrm{CTA})_{4} \cdot 2 \mathrm{H}_{2} \mathrm{O}\right](\mathbf{1}, \mathrm{CTA}=$ crotonic acid, Bpy $=4,4^{\prime}$-bipyridine) and $\left[\mathrm{Zn}_{2}(\mathrm{Bpy})(\mathrm{CTA})_{4}\right]$ (2). These were synthesized in different $\mathrm{pH}$ environments and were sensitive to UV light. Controlling the environments is a useful approach to building various fascinating multimetal clusters ${ }^{\mathbf{1 7}}$ as the joint point of different photochromic compounds. Here, their synthetic crystal structure, and photochromic and photoluminescence properties, are presented.

\section{Experimental section}

\section{Materials and instruments}

Analytical reagent grade $3 \mathrm{Zn}(\mathrm{OH})_{2} \cdot 2 \mathrm{ZnCO}_{3}$, crotonic acid, acetonitrile, and 4,4'-bipy were purchased from commercial 
sources. Water was deionized and distilled before use. Elemental analyses for $\mathrm{C}, \mathrm{H}$, and $\mathrm{N}$ were measured on an Elementar Vario EL III microanalyzer. A PLSSXE300C $300 \mathrm{~W}$ xenon lamp system equipped with an IR filter was used to prepare colored samples for UV-visible (UV-Vis), powder X-ray diffraction (PXRD), and electron spin resonance (ESR) studies, with a distance between the samples and the xenon lamp of around $40 \mathrm{~cm}$. UV-visible spectra were recorded using a PerkinElmer Lambda 900 UV/Vis/near-IR spectrophotometer equipped with an integrating sphere in the wavelength range 200-1000 $\mathrm{nm}$. $\mathrm{BaSO}_{4}$ plates were used as a reference (100\% reflection), on which the sample was coated as a finely ground powder. PXRD patterns were collected with a Rigaku MiniFlex II diffractometer powered at $30 \mathrm{kV}$ and $15 \mathrm{~mA}$ for $\mathrm{Cu}-\mathrm{K} \alpha$ radiation $(\lambda=1.54056 \AA)$ in the range $5-50^{\circ}$ at room temperature. Simulated PXRD patterns were achieved using Mercury Version 1.4 software (http://www.ccdc.cam.ac.uk/products/mercury/) and reported single-crystal X-ray diffraction data. Thermogravimetric analysis (TGA) experiments were performed on an NETZSCH STA 449F3 Jupiter thermogravimetric analyzer under $\mathrm{N}_{2}$ with the sample heated in an $\mathrm{Al}_{2} \mathrm{O}_{3}$ crucible at a rate of $15 \mathrm{~K} \mathrm{~min}^{-1}$. ESR spectra were recorded at the X-band frequency $(9.867 \mathrm{GHz})$ on a Bruker ELEXSYS E500 spectrometer. In situ photoluminescence (PL) determination was conducted on a single-grating Edinburgh FL920 fluorescence spectrometer equipped with a $450 \mathrm{~W}$ Xe lamp and a R928P PMT detector.

\section{Synthesis of compounds}

$\left[\mathbf{Z n}_{2}(\text { Bpy })_{1.5}(\text { CTA })_{4} \cdot 2 \mathbf{H}_{2} \mathbf{O}\right] \quad$ (1). A mixture of 4, $4^{\prime}$-bipy $(0.2 \mathrm{mmol})$, CTA $(0.8 \mathrm{mmol}), 3 \mathrm{Zn}(\mathrm{OH})_{2} \cdot 2 \mathrm{ZnCO}_{3}(0.1 \mathrm{mmol})$, and $\mathrm{H}_{2} \mathrm{O}(4.5 \mathrm{~mL})(\mathrm{pH} \approx 6.2)$ was sealed in a poly(tetrafluoroethylene)-lined stainless steel container under autogenous pressure, heated to $100{ }^{\circ} \mathrm{C}$ for 3 days, and then allowed to cool to room temperature. Colorless block-shaped crystals suitable for $\mathrm{X}$-ray analysis were obtained. Yield: $50 \%$ (based on $\mathrm{Zn}$ ) for 1, anal. calcd for $\mathrm{C}_{31} \mathrm{H}_{36} \mathrm{~N}_{3} \mathrm{O}_{10} \mathrm{Zn}_{2}$ : C, 50.20; H, 4.89; N, 5.66\%. Found: C, 50.00; H, 4.84; N, 5.41\%.

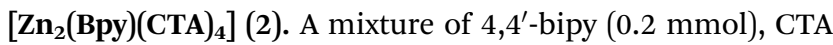
$(0.8 \mathrm{mmol}), 3 \mathrm{Zn}(\mathrm{OH})_{2} \cdot 2 \mathrm{ZnCO}_{3}(0.1 \mathrm{mmol}), \mathrm{H}_{2} \mathrm{O}(1.5 \mathrm{~mL})$, and $\mathrm{CH}_{3} \mathrm{CN}(3 \mathrm{~mL})(\mathrm{pH} \approx 5.8)$ was sealed in a poly(tetrafluoroethylene)-lined stainless steel container under autogenous pressure, heated to $100{ }^{\circ} \mathrm{C}$ for 3 days, and then allowed to cool to room temperature. Colorless block-shaped crystals suitable for $\mathrm{X}$-ray analysis were obtained. Yield: $80 \%$ (based on $\mathrm{Zn}$ ) for 2, anal. calcd for $\mathrm{C}_{26} \mathrm{H}_{28} \mathrm{~N}_{2} \mathrm{O}_{8} \mathrm{Zn}_{2}$ : C, 49.78; H, 4.49; N, 4.46\%. Found: C, 49.44; H, 4.47; N, 4.48\%.

\section{Crystal structure determination}

Single-crystal X-ray diffraction measurements of $\mathbf{1}$ and $\mathbf{2}$ were performed on a Rigaku Pilatus CCD, which was all equipped with Mo K $\alpha$ radiation $(\lambda=0.71073 \AA)$, using the $\omega$-scan technique to collect intensity data sets. Primitive structures were solved using direct methods and reduced using CrystalClear software. ${ }^{18}$ All hydrogen atoms were obtained by Fourier synthesis and using a full-matrix least-squares refinement on $F^{2}$ to obtain the final structure. All non-hydrogen atoms used
Table 1 Crystal data and structural refinements for compounds 1 and 2

\begin{tabular}{|c|c|c|}
\hline Complex & 1 & 2 \\
\hline Empirical formula & $\mathrm{C}_{31} \mathrm{H}_{36} \mathrm{~N}_{3} \mathrm{O}_{10} \mathrm{Zn}_{2}$ & $\mathrm{C}_{26} \mathrm{H}_{28} \mathrm{~N}_{2} \mathrm{O}_{8} \mathrm{Zn}_{2}$ \\
\hline$M_{\mathrm{r}}\left(\mathrm{g} \mathrm{mol}^{-1}\right)$ & 741.37 & 627.28 \\
\hline Crystal system & Triclinic & Triclinic \\
\hline Space group & $P \overline{1}$ & $P \overline{1}$ \\
\hline$a(\AA)$ & $7.7660(3)$ & $7.8730(4)$ \\
\hline$b(\AA)$ & $11.3054(5)$ & $9.2372(5)$ \\
\hline$c(\AA)$ & $19.0411(7)$ & $9.9610(5)$ \\
\hline$\alpha\left(^{\circ}\right)$ & $99.745(3)$ & $72.004(5)$ \\
\hline$\beta\left(^{\circ}\right)$ & $91.795(3)$ & $76.996(4)$ \\
\hline$\gamma\left({ }^{\circ}\right)$ & $91.783(3)$ & $76.160(4)$ \\
\hline$V\left(\AA^{3}\right)$ & $1645.72(11)$ & $659.95(6)$ \\
\hline$Z$ & 2 & 2 \\
\hline$D_{\mathrm{c}} / \mathrm{g} \mathrm{cm}^{-3}$ & 1.496 & 1.578 \\
\hline$\mu / \mathrm{mm}^{-1}$ & 1.517 & 1.869 \\
\hline$F(000)$ & 766 & 322 \\
\hline Reflections collected & 15047 & 6107 \\
\hline Unique reflections & 7997 & 3260 \\
\hline GOF & 1.032 & 1.020 \\
\hline$R_{1}^{a}[I>2 \sigma(I)]$ & 0.0361 & 0.0434 \\
\hline $\mathrm{w} R_{2}^{b}$ (all data) & 0.1832 & 0.1167 \\
\hline CCDC no. & 1542261 & 1542260 \\
\hline
\end{tabular}

anisotropic refinement and hydrogen atoms were generated on $\mathrm{C}$ and $\mathrm{N}$ atoms using the theory of hydrogenation method and refined using the $\mathrm{O}-\mathrm{H}$ distance restrained to a target value of $0.85 \AA$, the $\mathrm{H} \cdots \mathrm{H}$ distance restrained to $1.34 \AA$, and $U_{\mathrm{iso}(\mathrm{H})}=$ $1.5 U_{\text {eq }(\mathrm{O})}$. All calculations were performed using the Siemens SHELXTL version 5 crystallographic software package. ${ }^{19}$ Relevant crystal data, structural refinement results, and selected bond distances and angles for $\mathbf{1}$ and $\mathbf{2}$ are listed in Tables 1 and $\mathrm{S} 1, \dagger$ respectively.

Entries CCDC-1542261 and CCDC-1542260 contain supplementary crystallographic data for 1 and $2 . \dagger$

\section{Results and discussion}

\section{Crystal structure and characterization}

Compounds 1 and 2 were crystallized in the triclinic $P \overline{1}$ space group, as identified using single-crystal and powder XRD techniques (Fig. S1 $\dagger$ ). The thermogravimetric analysis (TGA) curves (Fig. S2 $\dagger$ ) showed that 1 had a weight loss of $4.40 \%$ in the temperature range $30-120{ }^{\circ} \mathrm{C}$, corresponding to the loss of two free water molecules (calcd, 4.85\%). Continued heating led to decomposition of the framework at $\sim 172{ }^{\circ} \mathrm{C}$. TGA data for 2 showed a stable platform in the temperature range $30-230{ }^{\circ} \mathrm{C}$, while continuous heating led to the breakdown of the framework.

\section{Crystal structure}

For 1, there were two crystallographically independent $\mathrm{Zn}$ (II) centers, one and a half 4,4'-bipy ligands, four CTA ligands and two free water molecules in the asymmetric unit (Fig. 1a). One $\mathrm{Zn}$ atom (Zn1) was four-coordinate with two nitrogen atoms (Zn1-N, 2.0527-2.0763 ̊) from two 4,4'-bipy ligands and two 


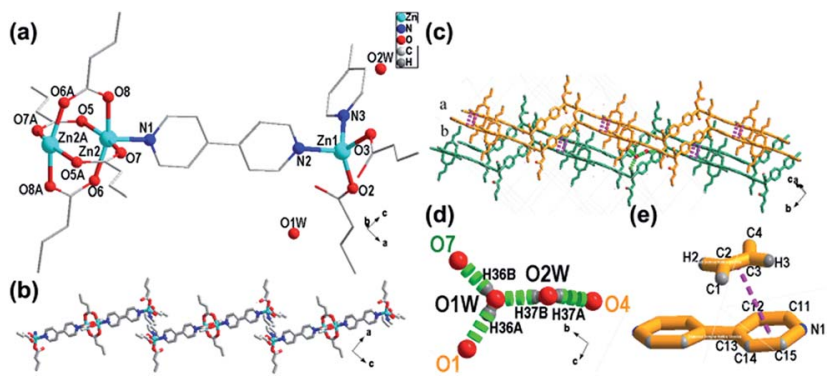

Fig. 1 Structure of compound 1: (a) asymmetric unit; symmetry codes: (1) $-1-x, 1-y,-z$; (2) $1-x, 3-y, 1-z$. (b) View of 1-D trapezoidal chain structure along $b$ axis; and (c) 3-D packing structure. Hydrogen bonds ((d), green dashed line) and $\pi \cdots \pi$ stacking interaction ((e), pink dashed line) are shown.

oxygen atoms (Zn1-O, 1.9292-1.9756 ̊̊) from two CTA ligands, while the $\mathrm{Zn} 2$ atom had a rectangular pyramidal coordination sphere, with four oxygen atoms from four CTA ligands ( $\mathrm{Zn} 2-\mathrm{O}$, 2.0191-2.1162 $\mathrm{\AA})$ and one nitrogen atom ( $\mathrm{Zn} 2-\mathrm{N}, 2.0402 \AA)$ from one 4,4'-bipy ligand. Two Zn2 atoms were bridged by carboxylate groups to form binuclear $\mathrm{Zn}$ units with a neighboring $\mathrm{Zn} \cdots$ Zn separation of $2.9308(5) \AA$. The $4,4^{\prime}$-bipy ligands were alternately connected with the binuclear Zn units and Zn1 ion. Stairlike 1D chain structures were formed along $b$ axis in 1 (Fig. 1b). The center-to-center distance between the nearest pyridinium ring and double bond of CTA was 3.5230(1) $\AA$ and the angle between the pyridinium plane and CTA plane was 11.91(15) (Fig. 1e). Accordingly, $\pi \cdots \pi$ stacking interactions between the pyridinium ring and CTA were not overlooked. As shown in Fig. 1c, the distance between two different adjacent chains

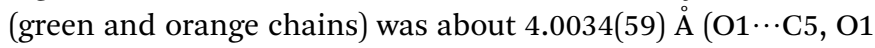
in the green chain, $\mathrm{C} 5$ in the orange chain). Consequently, they were connected by water molecules through $\mathrm{O}(1 \mathrm{w})-\mathrm{H}(36 \mathrm{~A}) \cdots$ $\mathrm{O}(1), \mathrm{O}(1 \mathrm{w})-\mathrm{H}(36 \mathrm{~B}) \cdots \mathrm{O}(7), \mathrm{O}(2 \mathrm{w})-\mathrm{H}(37 \mathrm{~A}) \cdots \mathrm{O}(4)$, and $\mathrm{O}(2 \mathrm{w})-$ $\mathrm{H}(37 \mathrm{~B}) \cdots \mathrm{O}(1 \mathrm{w})$. The hydrogen bond distances and angles ${ }^{20}$ are summarized in Table 2 . Chains connected via $\pi \cdots \pi$ interactions $\mathrm{s}^{21-23}$ were further linked though hydrogen bonding interactions with water molecules, leading to a 3D supramolecular structure (Fig. 1c).

Only one crystallographically independent $\mathrm{Zn}$ (II) center (Fig. 2a) existed, with two CTA ligands and one 4,4'-bipy ligand in an asymmetric unit of compound 2. Each $\mathrm{Zn}$ (II) center was coordinated by one nitrogen atom ( $\mathrm{Zn}-\mathrm{N}, 2.0389)$ from the 4,4'bipy ligand and four oxygen atoms ( $\mathrm{Zn}-\mathrm{O}, 2.0335-2.0708)$ from four different CTA ligands. Every two $\mathrm{Zn}$ atoms were bridged by carboxylate groups to form a classic dinuclear unit with a neighboring $\mathrm{Zn} \cdots \mathrm{Zn}$ separation of 2.8996(1) $\AA$ (Fig. 2a). These

Table 2 Hydrogen bond distances $(\AA)$ and angles $\left(^{\circ}\right)$ in compound 1

\begin{tabular}{llll}
\hline Hydrogen bond & Distance $(\AA)$ & Hydrogen bonds & Angles $\left(^{\circ}\right)$ \\
\hline O4-H37A & $2.06(24)$ & H36A-O1W $\cdots$ H37B & $130.63(1861)$ \\
O1W-H37B & $2.06(33)$ & H36B-O1W $\cdots$ H37B & $119.96(1074)$ \\
O7-H37B & $2.18(156)$ & H37B-O2W-H37A & $109.50(383)$ \\
O1-H36A & $2.11(314)$ & H36A-O1W-H36B & $108.41(3467)$
\end{tabular}



Fig. 2 Structure of compound 2: (a) asymmetric unit; symmetry codes: (1) $1-x, 2-y,-z$; (2) $2-x, 2-y, 1-z$. (b) 1-D linear chain structure along a axis; (c) packing structure viewed along $b$ axis; and (d) $\pi \cdots \pi$ stacking interaction between a pyridinium ring and the CTA double bond.

classic dinuclear units were further linked to a 4,4'-bipy ligand, forming a 1-D $-\left[\mathrm{Zn}_{2}(\mathrm{CTA})_{4}-\mathrm{Bpy}-\mathrm{Zn}_{2}(\mathrm{CTA})_{4}\right]_{n^{-}}$linear chain structure along the a axis (Fig. 2b). In compound 2, 4,4'-bipy ligands act as screws to connect units. The nearest distance of two neighboring chains (C3‥C14) was about 3.3239(36) $\AA$, and the center-to-center $\pi \cdots \pi$ distance (pink dashed line shown in Fig. 2d) between the pyridinium ring and CTA double bond was $3.3624(2) \AA$, with these two planes forming an angle of $6.20(4)^{\circ}$ (Fig. 2d). Structural analysis of 2 revealed the presence of a $\pi \cdots \pi$ stacking interaction between the pyridinium ring in 4,4'-bipy and the double bond in CTA from different chains. Finally, these chains formed a 3-D crystal structure along the $b$ axis (Fig. 2c).

As we proposed previously, the coordination assembly of one conjugated ligand (as an electron acceptor), one ligand with groups containing lone pairs of electrons (as an electron donor), and a metal center could obtain photochromic compounds. ${ }^{24}$ Compounds 1 and 2 were not exceptions, showing electron transfer behavior under photoirradiation.

\section{Photochromic properties}

As shown in Fig. 3, bulk colorless crystals of 1 turned light purple after irradiation with a $300 \mathrm{~W}$ Xe lamp under ambient conditions. The photoresponse range was $\sim 330-370 \mathrm{~nm}$ for $\mathbf{1}$, with an optimal wavelength of about $340 \mathrm{~nm}$. The UV-Vis absorption spectrum showed that two new broad absorption

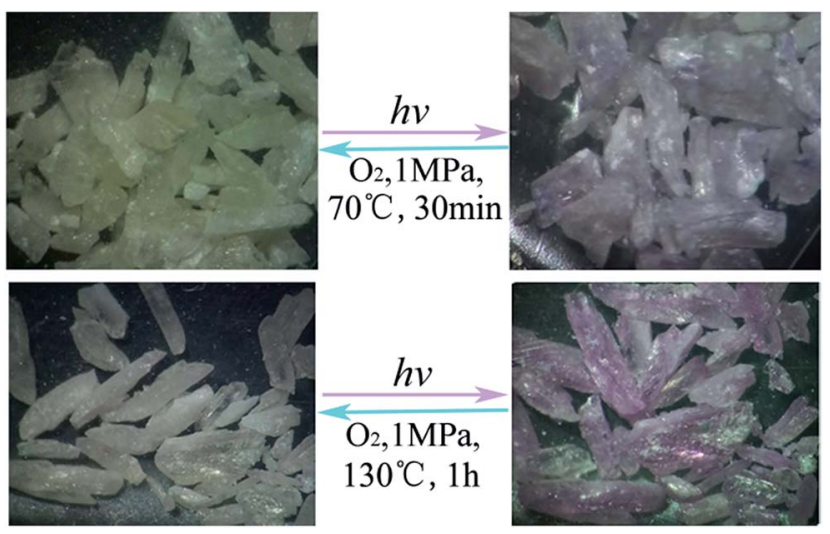

Fig. 3 Photochromism of 1 (top) and 2 (bottom). 
bands centered at $\sim 385$ and $562 \mathrm{~nm}$ emerged and gradually grew larger with increasing irradiation time (Fig. 4). ESR indicated that a symmetric single-line radical signal with a $g$ value of 2.0038 emerged (Fig. 5) during the photochromic process, which was very close to that of a free electron (2.0023). This demonstrated that the photochromic process of $\mathbf{1}$ originated from photo-induced free radical generation and was an electron-transfer process. The photoproduct of 1, 1P, could be bleached slowly in the dark under ambient conditions (Fig. S4 $\dagger$ ), but was also easily bleached by annealing under $\mathrm{O}_{2}(1$ $\mathrm{MPa}$ ) at $70{ }^{\circ} \mathrm{C}$ for $30 \mathrm{~min}$. These photoinduced colorationdecoloration processes were reversible, which demonstrated that $\mathbf{1}$ had photochromism characteristics. Compound $\mathbf{2}$ also underwent a color change from colorless to purple after photoirradiation using the same energy xenon lamp under ambient conditions (Fig. 3). The photoresponse range was $\sim 330-370 \mathrm{~nm}$ for 2, with an optimal wavelength of about $340 \mathrm{~nm}$. The UV-Vis absorption spectrum showed two new broad absorption bands centered at $\sim 385$ and $572 \mathrm{~nm}$, which grew larger with increasing irradiation time (Fig. 4). An ESR study indicated a symmetric single-line radical signal with a $g$ value of 2.0038 emerged (Fig. 5) in the photochromic process, and the generation of radicals. The photoproduct of $\mathbf{2}, \mathbf{2 P}$, could be bleached slowly in the dark under ambient conditions (Fig. S4†), but was also


Fig. 4 UV-Vis absorption spectra of 1 (top) and 2 (bottom), which are dependent on illumination under ambient conditions.

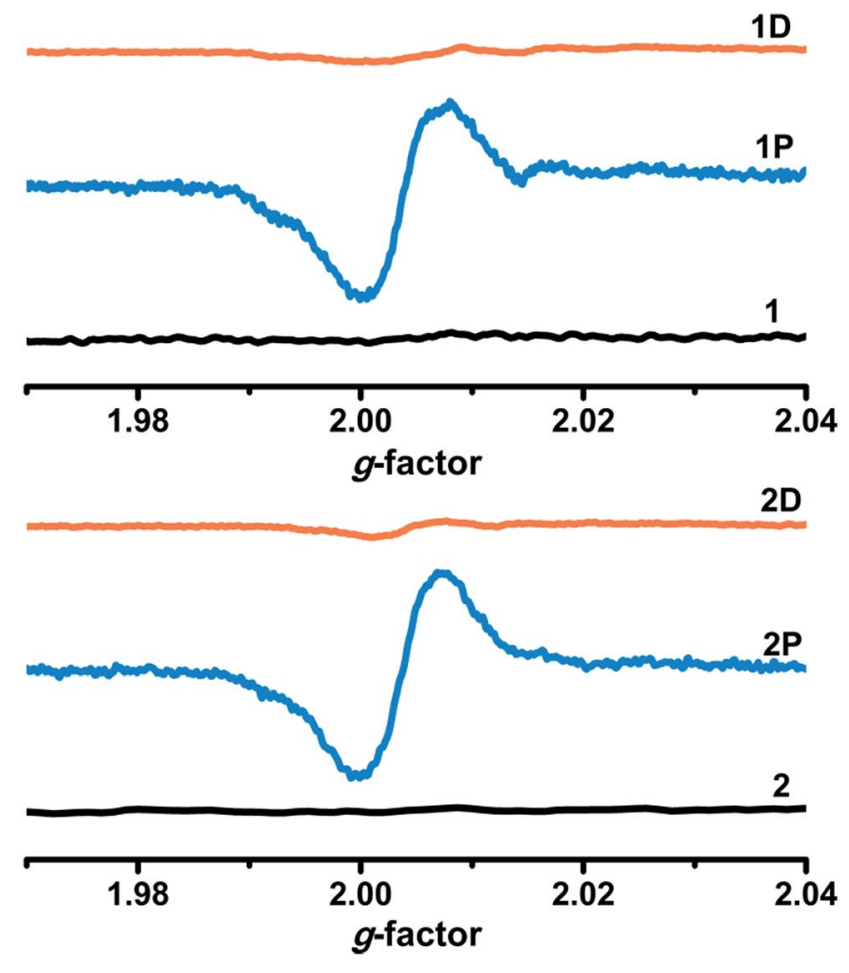

Fig. 5 ESR spectra of 1 and 2 before and after irradiation (1P, 2P) and decolored (1D, 2D) under ambient conditions.

bleached after annealing at $130{ }^{\circ} \mathrm{C}$ for $2 \mathrm{~h}$ in air or after annealing at $130{ }^{\circ} \mathrm{C}$ under $\mathrm{O}_{2}(1 \mathrm{MPa})$ for $1 \mathrm{~h}$ (Fig. S6 $\dagger$ ).

The UV-Vis spectra of $3 \mathrm{Zn}(\mathrm{OH})_{2} \cdot 2 \mathrm{ZnCO}_{3}$ and crotonic acid (CTA) (Fig. S3†) showed no obvious changes in $3 \mathrm{Zn}(\mathrm{OH})_{2}$ $\cdot 2 \mathrm{ZnCO}_{3}$ and CTA before and after irradiation for $2 \mathrm{~h}$. Therefore, according to previous work, the photochromic process should be an electron-transfer process from CTA (electron donor) to 4,4'-bipy (electron acceptor). The nearest distances between the carboxylate oxygen atom and the nitrogen atom of the pyridinium ring were 3.0244(34) Å for 1 and 3.0761(32) A for 2. As these distances were almost identical, the influence of distance on electron transfer in the two compounds was not distinct. However, $\pi \cdots \pi$ stacking interactions between the pyridinium rings and CTA double bonds with their center-tocenter distances of 3.5230(1) $\AA$ for 1 and 3.3624(2) $\AA$ for 2 showed that they might be more helpful for generating free radicals and electron transfer in 2 .

The time-dependent UV-Vis spectra data underwent linear fitting at $562 \mathrm{~nm}$ for 1 and $572 \mathrm{~nm}$ for 2 (Fig. 6) and illustrated that their photochromic behaviors followed first-order reaction kinetics, which can be explained using the following equation:

$$
\ln \left(A_{0}-A_{\infty}\right) /\left(A_{t}-A_{\infty}\right)=K t
$$

where $K$ is the first-order reaction kinetics rate constant, and $A_{0}$, $A_{t}$, and $A_{\infty}$ are the absorbances before irradiation, after irradiation for time $t$, and at the end of the reaction, respectively. ${ }^{25,26}$ The fitting rate constants $\left(K_{\text {obs }}\right)$ for compounds 1 and 2 were $\sim 9.60 \times 10^{-4}$ and $1.14 \times 10^{-3} \mathrm{~s}^{-1}$, respectively. According to the UV-Vis spectra, the conversion rate of these two complexes 

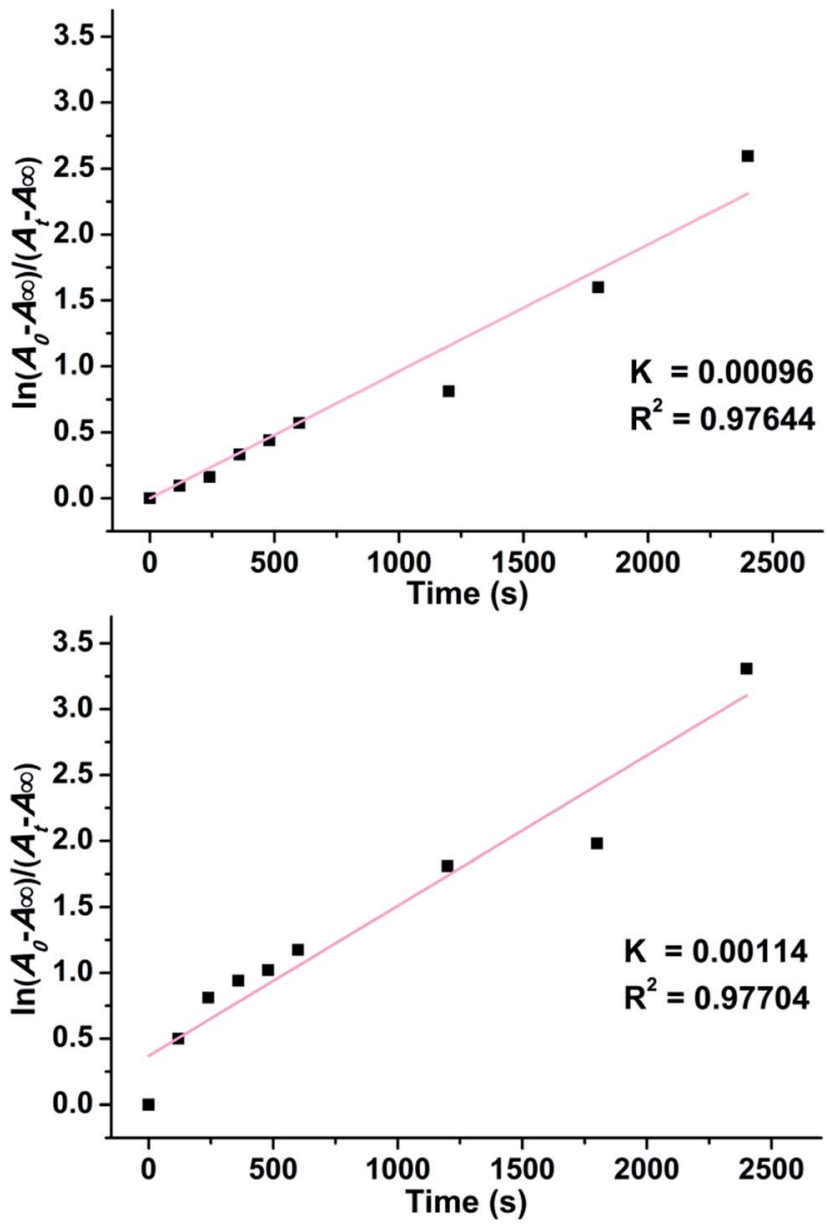

Fig. 6 First-order kinetics of photoinduced coloration process of 1 (top) and 2 (bottom) under ambient conditions.

at the beginning was faster than at a later time. This phenomenon was caused by photochemical reactions occurring on surfaces initially and then inside in the final stages. ${ }^{27}$ This showed that the coloration speed of $\mathbf{2}$ was faster than that of $\mathbf{1}$ in Fig. 6. Consequently, the $\pi \cdots \pi$ stacking interaction between the pyridinium ring and CTA double bond should be the main factor in the color of compound $\mathbf{2}$ changing faster than that of $\mathbf{1}$.

\section{Photoluminescence properties}

The photochromic process is generally associated with a change in the fluorescence properties. ${ }^{5,28-30}$ As shown in Fig. 7, compounds 1 and 2 had two broad emissive bands upon excitation with a $370 \mathrm{~nm}$ Xe light under ambient conditions, centered at $453 \mathrm{~nm}$ for 1 and $446 \mathrm{~nm}$ for 2, respectively. BPY and CTA showed PL emission bands with peaks at $434 \mathrm{~nm}$ and $469 \mathrm{~nm}$, respectively (Fig. S7 †). By comparing the peak values of $\mathbf{1}, \mathbf{2}$, BPY, and CTA, the conclusion that the PL of 1 and 2 can be a preliminary definition due to the combination of emission from BPY and CTA can be obtained. The time-dependent PL spectra of 1 and 2 showed that the PL intensity decreased gradually with increasing irradiation time, reaching about $47.1 \%$ for 1 and $41.8 \%$ for 2 of the initial value after $120 \mathrm{~min}$.
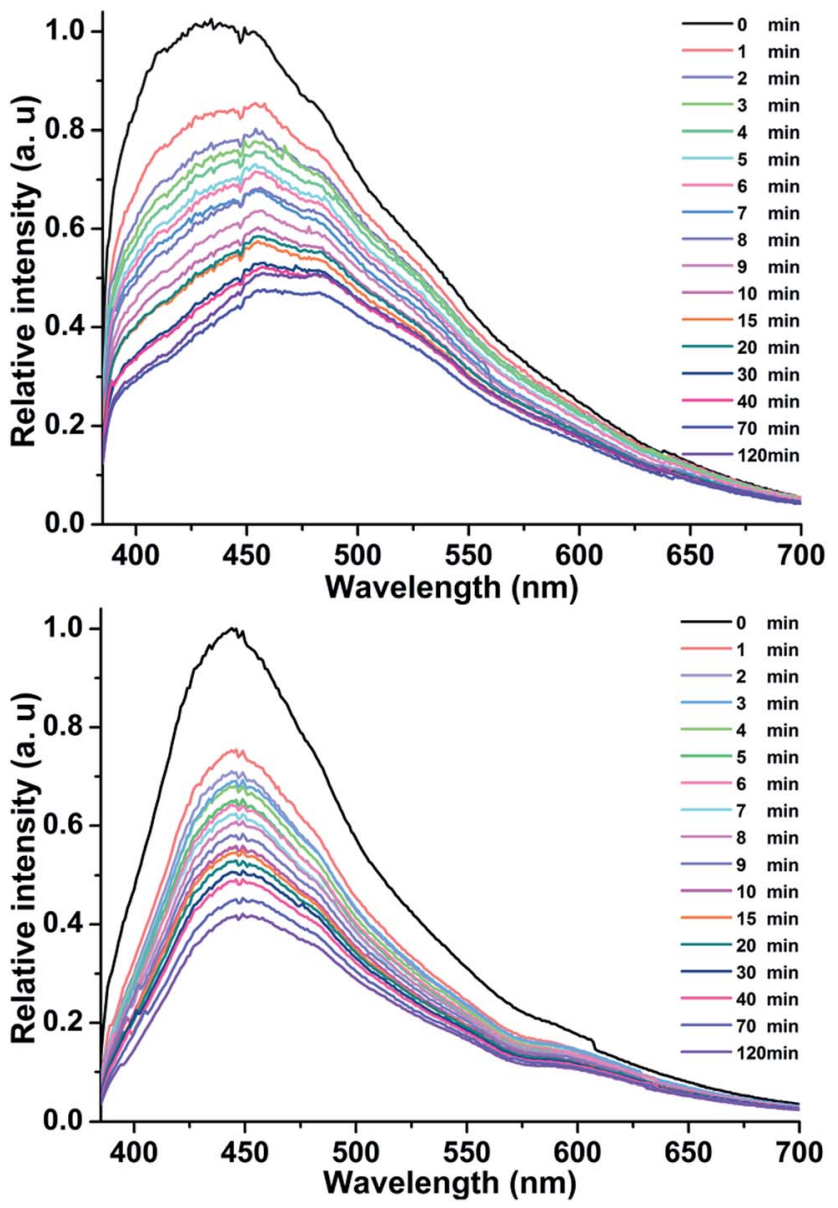

Fig. 7 Time-dependent fluorescence spectra ( $\lambda_{\mathrm{ex}}=370 \mathrm{~nm}$ ) of 1 (top) and 2 (bottom) under ambient conditions.

When the emission values did not change further with increasing irradiation time, the colors of compounds remained stable with extended irradiation times. Accordingly, the UV-Vis absorption data peaked. This further proved that PL quenching was also accompanied by the ET process. Such a phenomenon is common for compounds that can undergo ET photochromism. The different PL intensity decreases also corresponded with the coloration processes in $\mathbf{1}$ and 2, which further supported that ET was significantly affected by $\pi \cdots \pi$ stacking interactions between the pyridinium ring and CTA double bond.

\section{Conclusions}

In summary, two new photochromic coordination compounds with non-photochromic ligands were prepared and characterized. This work proposed using multi-metal units as connections in photochromic coordination compounds with non-photochromic ligands, which has enriched this system. Meanwhile, the $\pi \cdots \pi$ interactions proved to be beneficial for electron transfer in these photochromic compounds. These results will aid the design and synthesis of new photochromic compounds with different multinuclear metal centers and high performance. 


\section{Acknowledgements}

We gratefully acknowledge financial support from the National Science Function of China (grant numbers 21373225, 21221001, and 21471149), the NSF of Fujian Province (grant numbers 2014J07003 and 2014J01065), and the Strategic Priority Research Program of the Chinese Academy of Sciences.

\section{Notes and references}

1 (a) Q. Wang and D. Ma, Chem. Soc. Rev., 2010, 39, 2387-2398; (b) G.-H. Alexis, U. Manuel, M. Dragos, T. Evgenii, S. Jutta, G. Lutz, B. David, S. Peter and H. Stefan, J. Am. Chem. Soc., 2017, 139, 335-341; (c) S. Lee, Y. You, K. Ohkubo, S. Fukuzumi and W. Nam, Chem. Sci., 2014, 5, 1463-1474; (d) P.-X. Li, M.-S. Wang, M.-J. Zhang, C.-S. Lin, L.-Z. Cai, S.-P. Guo and G.-C. Guo, Angew. Chem., Int. Ed., 2014, 53, 11529-11531.

2 (a) I. F. A. Mariz, F. Siopa, C. A. B. Rodrigues, C. A. M. Afonso, X. Chen, J. M. G. Martinho and E. M. S. Maçôas, J. Mater. Chem. C, 2015, 3, 10775-10782; (b) Y.-J. Cui, Y.-F. Yue, G.-D. Qian and B.-L. Lin, Chem. Rev., 2012, 112, 1126-1162.

3 Z.-C. Hu, B. J. Deibert and J. Li, Chem. Soc. Rev., 2014, 43, 5815-5840.

4 K. K.-W. Lo, K. Y. Zhang, S.-K. Leung and M.-C. Tang, Angew. Chem., Int. Ed., 2008, 47, 2213-2216.

5 C.-J. Zhang, Z.-W. Chen, R.-G. Lin, M.-J. Zhang, P.-X. Li, M.-S. Wang and G.-C. Guo, Inorg. Chem., 2014, 53, 847-851.

6 Z.-Y. Fu, Y. Chen, J. Zhang and S.-J. Liao, J. Mater. Chem., 2011, 21, 7895-7897.

7 I. Stassen, N. Burtch, A. Talin, P. Falcaro, M. Allendorf and R. Ameloot, Chem. Soc. Rev., 2017, 46, 3185-3241.

8 T. Gong, X. Yang, J.-J. Fang, Q. Sui, F.-G. Xi and E.-Q. Gao, ACS Appl. Mater. Interfaces, 2017, 9, 5503-5512.

9 K. Boopathy and P. Ramasamy, J. Mol. Struct., 2015, 1080, 3743.

10 E. Pershagen and K. E. Borbas, Coord. Chem. Rev., 2014, 273, $30-46$.

11 D.-P. Yan, H.-J. Yang, Q.-Y. Meng, H.-Y. Lin and M. Wei, Adv. Funct. Mater., 2014, 24, 587-594.

12 S. Saha, G. Das, J. Thote and R. Banerjee, J. Am. Chem. Soc., 2014, 136, 14845-14851.

13 (a) G. J. Kavarnos and N. J. Turro, Chem. Rev., 1986, 86, 401449; (b) M. R. Wasielewski, Chem. Rev., 1992, 92, 435-461.
14 K. V. Rao, K. K. R. Datta, M. Eswaramoorthy and S. J. George, Adv. Mater., 2013, 25, 1713-1718.

15 (a) Q.-X. Yao, L. Pan, X.-H. Jin, J. Li, Z.-F. Ju and J. Zhang, Chem.-Eur. J., 2009, 15, 11890-11897; (b) Q.-X. Yao, Z.-F. Ju, X.-H. Jin and J. Zhang, Inorg. Chem., 2009, 48, 1266-1268; (c) X.-H. Jin, J.-K. Sun, X.-M. Xu, Z.-H. Li and J. Zhang, Chem. Commun., 2010, 46, 4695-4697.

16 M. D. Allendorf, C. A. Bauer, R. K. Bhakta and R. J. T. Houka, Chem. Soc. Rev., 2009, 38, 1330-1352.

17 J. Heine and K. Müller-Buschbaum, Chem. Soc. Rev., 2013, 42, 9232-9242.

18 CrystalClear, version 1.35, Software User's Guide for the Rigaku $R$-Axis, and Mercury and Jupiter CCD Automated X-ray Imaging System, Rigaku Molecular Structure Corporation, Utah, 2002.

19 SHELXTL Reference Manual, version 5, Siemens Energy \& Automation Inc., Madison, WI, 1994.

20 J. Wang, S.-L. Li and X.-M. Zhang, ACS Appl. Mater. Interfaces, 2016, 8, 24862-24869.

21 R. Li, S.-H. Wang, Z.-F. Liu, X.-X. Chen, Y. Xiao, F.-K. Zheng and G.-C. Guo, Cryst. Growth Des., 2016, 16, 3969-3975.

22 C. Janiak, J. Chem. Soc., Dalton Trans., 2000, 3885-3896.

23 H.-T. Feng, J.-B. Xing, Y.-S. Zheng, B. Pan, C. Zhang, L. Wang and Y. Xie, Chem. Mater., 2015, 27, 7812-7819.

24 (a) Z.-Q. Liu, Y. Zhao, Y. Deng, X.-D. Zhang, Y.-S. Kang, Q.-Y. Lu and W.-Y. Sun, Sens. Actuators, B, 2017, 250, 179188; (b) Y.-L. Li, Y. Zhao, P. Wang, Y.-S. Kang, Q. Liu, X.-D. Zhang and W.-Y. Sun, Inorg. Chem., 2016, 55, 1182111830; (c) Y. Deng, P. Wang, Y. Zhao, Y.-S. Kang and W.-Y. Sun, Microporous Mesoporous Mater., 2016, 227, 39-47.

25 R.-G. Lin, G. Xu, G. Lu, M.-S. Wang, P.-X. Li and G.-C. Guo, Inorg. Chem., 2013, 52, 1199-1205.

26 R.-G. Lin, G. Xu, G. Lu, M.-S. Wang, P.-X. Li and G.-C. Guo, Inorg. Chem., 2014, 53, 5538-5545.

27 M. Li, L.-J. Yuan and Z.-Y. Fu, Inorg. Chem. Commun., 2015, $57,58-61$.

28 S.-Q. Zhang, F.-L. Jiang, Y. Bu, M.-Y. Wu, J. Ma, X.-C. Shan, K.-C. Xiong and M.-C. Hong, CrystEngComm, 2012, 14, 6394-6396.

29 Z.-F. Wu, B. Tan, J.-Y. Wang, C.-F. Du, Z.-H. Deng and X.-Y. Huang, Chem. Commun., 2015, 51, 157-160.

30 S.-H. Wang, F.-K. Zheng, M.-J. Zhang, Z.-F. Liu, J. Chen, Y. Xiao, A.-Q. Wu and G.-C. Guo, Inorg. Chem., 2013, 52, 10096-10104. 